\title{
Experimental Research on Fracture Mechanism of Microdrill
}

\author{
Ying Chen ${ }^{\mathrm{a}}$, Yanhong Sun ${ }^{\mathrm{b}^{*}}$ and Hong Yang ${ }^{\mathrm{c}}$ \\ College of Mechanical Engineering, Jilin Engineering Normal University, Changchun 130052, \\ China \\ a823068684@qq.com, b343175460@qq.com, '948855267@qq.com \\ ${ }^{*}$ The corresponding author
}

\begin{abstract}
Keywords: Microdrill; Fracture mechanism; Static strength failure; Fatigue failure; Experiment research
\end{abstract}

\begin{abstract}
By drilling a large number of experiments, the drilling force, bit positioning error and other data, Using high resolution camera and microscope observation techniques to obtain microdrill digital photos, based on the structural analysis of micro drill, the stress model is established, Based on the combination of experimental research and theoretical calculation, the combination of quantitative and qualitative analysis. The fracture mechanism of micro drill is defined from three aspects, such as the fracture observation of micro drill, the calculation of ultimate stress and the calculation of stress cycle. The results show that the fracture of micro drill is that the drilling force reaches the strength limit of the material, which leads to the failure of the static strength.
\end{abstract}

\section{Introduction}

Although experts and scholars have done a lot of theoretical research and experimental analysis on the fracture of microdrill in micro hole drilling, Online monitoring drilling force, spindle motor current and cutting heat and temperature, AE signal and power signal and displacement signal and other signals[1-4], is to control the micro drill drilling process and real-time monitoring of the state, However, the research on the fracture mechanism of micro drill is less, this paper will study the fracture mechanism of micro drill in detail.

\section{Experimental System and Processing Conditions}

This experiment is in the ZG high speed precision brush drill, the measurement system is shown in Fig.1. The strain gauge is mounted on the drill table and the workpiece is clamped on the strain gauge. In the process of drilling, axial force and torque of the dynamometer is measured by the strain gauge, the strain sensor will transformate force signal into voltage signal by the bridge circuit and transmitted to NI6013 data acquisition card, complete the signal A/D conversion, the analog signal into digital micro signal; data acquisition card digital output the signal is input to the industrial control computer, analysis, processing, display and storage of the signal by the signal processing module of the collected; in the control part, the instruction issued by the computer, transfer to the microcontroller through the serial communication, the pulse signal emitted by the microcontroller through the power amplifier to the stepper motor, so as to realize the control the axial feed motion of microdrill[5].

This experiment is carried out in the high speed brushless precision drill, to measure the drilling axial force and drilling torque signal using strain gauge sensor. The main drilling conditions for the diameter of 0.5 high-speed steel twist drill, H62 brass workpiece material, drilling depth of 2, spindle speed of 22000 , feed rate, 40, oil lubrication. 


\section{Research on Fracture Mechanism of Micro Drill}

There are many reasons for the fracture of micro drill, and the final reason is that the micro drill bit is broken due to the limit stress of the bit [5-6]. But the limit stress of micro drill is more than static strength limit or fatigue strength limit.

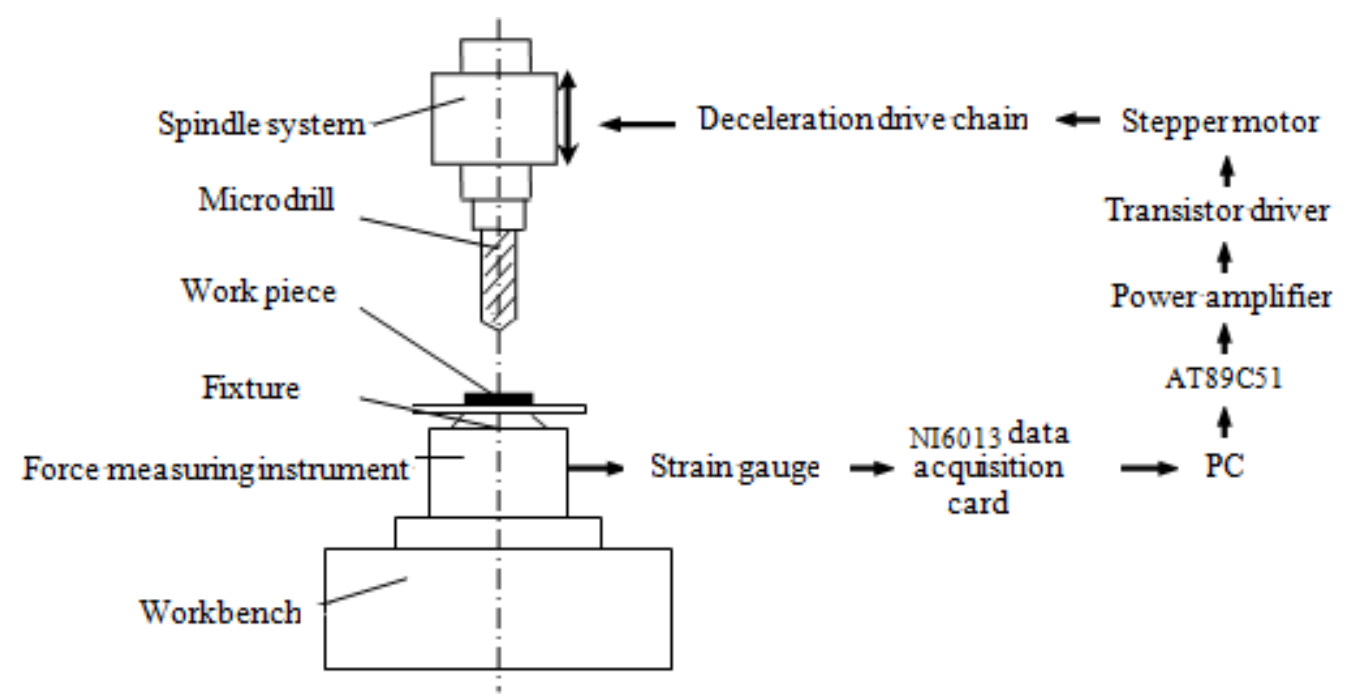

Figure 1. Structure diagram of experimental device

The characteristics of component under alternating stress fatigue failure has three main points: Due to the shape of the components and materials are not uniform and other reasons, the local stress of components is particularly high; In the crack formation, the two sides of a crack under alternating stress and separate, sometimes pressed repeatedly, the formation of smooth zone; the fatigue failure can be occurred under the given alternating stress[7].

In this paper, the fracture mechanism of micro drill is studied in three ways: fracture analysis of microdrill and the calculation of limit stress and stress cycle[8].

Observation and Analysis of Micro Drill. Fig. 2 is a random set of amplified micro drill fracture photographs, $\mathrm{N}$ indicates the number of holes before the break, representing the life of the micro drill.
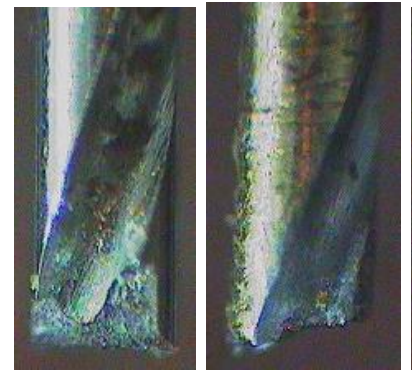

$\mathrm{n}=8$

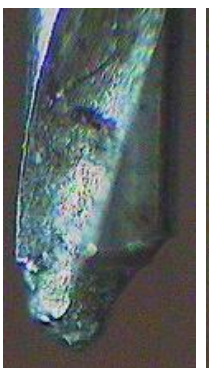

$\mathrm{n}=28$

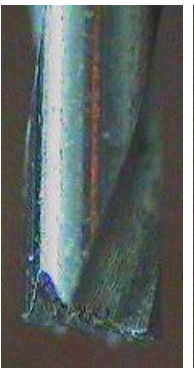

$\mathrm{n}=36$

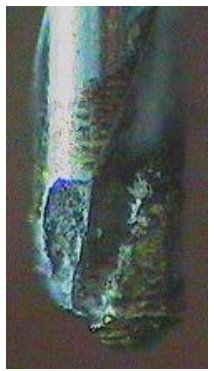

$\mathrm{n}=72$

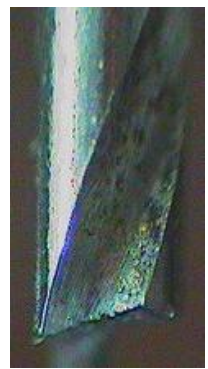

$\mathrm{n}=165 \quad \mathrm{n}=233$

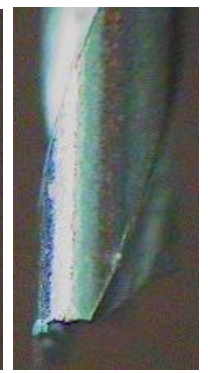

(a)Axial view 


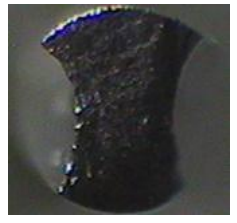

$\mathrm{n}=8$

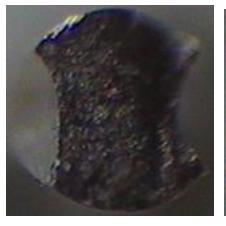

$\mathrm{n}=13$

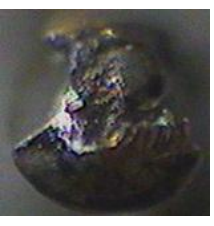

$\mathrm{n}=28$

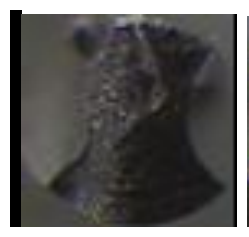

$\mathrm{n}=36$

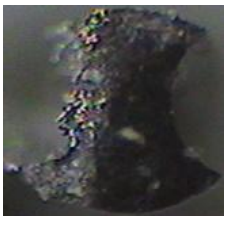

$\mathrm{n}=72$

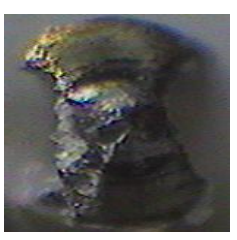

$\mathrm{n}=165$

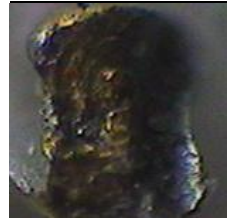

$\mathrm{n}=233$

(b) Cross section view

Figure 2. Microdrill fracture view

Fig. 2 (a) observation showed that most of the fracture occurred in the middle of the spiral groove to the root of the spiral groove, and the angle between the normal section of the fracture section and the axis of the micro drill was about $0^{\circ}$ to $50^{\circ}$. After amplification of 250 times, the size of the fracture surface was almost unchanged, indicating that there was no obvious plastic deformation before the fracture of the drill bit. But the cross-sectional view of fracture Fig. 2 (b) It was found that there was no obvious smooth area in the fracture of the micro drill. Therefore, the fracture characteristics of microdrills do not have the characteristics of fatigue failure. It is concluded that the fracture of micro drill is not caused by the structural fatigue, but it is likely to be damaged by static strength[9].

Calculation and Analysis of the Ultimate Stress of Micro Drill. Under the condition of micro fracture analysis, the limit stress of the micro drill is calculated to determine the failure type.

The Calculation of Stress of Micro Drill. In the process of microdrill drilling, the micro drill must bear axial force, torque and lateral force, which will produce axial compression, torsion around the axis, lateral bending, etc. The stress on any section includes four parts: normal stress, shear stress, compressive stress and torsional shear stress. Micro drill flute outer edge is a dangerous position of stress concentration, the drill bit is abstracted as equivalent diameter De cylinder, the stress analysis of the material mechanics, mathematical models of Formula 1 limit sMtress calculation of micro drill.

$$
\sigma_{c a}=\sqrt{\left(\frac{4 F}{\pi D_{e}^{2}}+\frac{3 E D_{e} r}{2 L^{2}}\right)^{2}+4\left(\frac{16 M n}{\pi D_{e}^{3}}\right)^{2}}
$$

Limit Stress Calculation of Micro Drill. The 50 micro drill drilling experiment, drilling hole is removed only 1 5 special case of breaking, extracting the remaining 36 branch of micro drill close to various experimental data into the broken type, of which the average drill to break the first 5 holes of the value calculation of the ultimate stress see Table 1.

Table 1 Experimental data of the micro drill

\begin{tabular}{ccccc}
\hline \multirow{2}{*}{ Number of holes } & \multirow{2}{*}{ Axial force Fd[N] } & TorqueMnd[mm] & Drilling positioning error & $\sigma_{\max }[\mathrm{MPa}]$ \\
\hline 8 & 19.89 & 3.16 & 112.9 & 2202.4 \\
13 & 5.483 & 5.609 & 89.8 & 2167.3 \\
28 & 7.338 & 6.237 & 57.4 & 979.5 \\
36 & 28.913 & 5.175 & 55.2 & 958.6 \\
72 & 42.08 & 7.365 & 85.8 & 1375.4 \\
165 & 25.12 & 3.613 & 69.7 & 735.6 \\
233 & 56.13 & 5.288 & 70.6 & 1121.4 \\
$\begin{array}{c}\text { The mean of 36 } \\
\text { micro drill }\end{array}$ & 25.839 & 6.119 & 84.361 & 1104.7 \\
experimental data & & & & \\
\hline
\end{tabular}
2 . 
Table 2 Microdrill material performance index

\begin{tabular}{cccccccc}
\hline Index & $\begin{array}{c}\text { Density } \\
{\left[\mathrm{kg} / \mathrm{m}^{3}\right]}\end{array}$ & $\begin{array}{c}\text { Compressive } \\
\text { strength }[\mathrm{MPa}]\end{array}$ & $\begin{array}{c}\text { Ultimate } \\
\text { tensile } \\
\text { strength } \\
{[\mathrm{MPa}]}\end{array}$ & $\begin{array}{c}\text { Bending } \\
\text { strength } \\
{[\mathrm{MPa}]}\end{array}$ & $\begin{array}{c}\text { Torsional } \\
\text { strength } \\
{[\mathrm{MPa}]}\end{array}$ & $\begin{array}{c}\text { Elastic } \\
\text { modulus } \\
{[\mathrm{GPa}]}\end{array}$ & $\begin{array}{c}\text { Poisson } \\
\text { ratio } \mu\end{array}$ \\
\hline Value & 8700 & 3500 & 3500 & 3500 & 2300 & 210 & 0.3 \\
\hline
\end{tabular}

The fatigue strength limit of the component is far less than that of the static strength limit, that is to say, the ultimate stress should be different from that of the material. But the micro drill material intensity limit and Table 2 microdrills close to break, the limit ratio of the stress and the average stress limit rate is smaller in the $4.75 \sim 1.58$, and do not have the features of fatigue fracture, so the calculation results further confirmed that micro drill breakage belongs to the static strength of broken inference.

Cycle Number Calculation of the Micro Drill Stress. The cyclic base is usually used before the fatigue failure of steel members $N_{0}=2 \times 10^{6} \sim 10^{7} \quad$ [10].

The maximum service life in experiment is broken before drilling 233 hole. The maximum number of stress cycles in the actual drilling process is

$$
N_{\max }=\frac{22000(r / \mathrm{min})}{60(s)} \times \frac{2}{40} \times 60(s) \times 233=256300=2.563 \times 10^{5}<<N_{0}
$$

The results show that the number of stress cycles is much smaller than that of the fatigue limit of the material itself, which further confirms that the fracture of the micro drill is not the result of fatigue fracture.

\section{Conclusion}

The calculation and analysis show that: When the micro drill is broken, the fracture surface does not show the appearance of the smooth area and the rough area with obvious boundary due to the fatigue damage due to long time alternating stress. Based on the third strength theory, the stress model of microdrill is relatively close to that of the microdrill. With the result of fatigue damage should be much smaller than the static ultimate strength of anastomosis; The maximum number of stress cycles in the experiment is far less than that of the steel components before the fatigue failure. The above calculation and analysis results show that the micro drill break is not fatigue failure, but it should be the static strength failure, that is, the fracture of the micro drill is the strength of the drill bit to achieve the strength limit of the material.

\section{References}

[1] Y.X. Cui, Research on Micro-drilling Online Monitoring Based on Double Neural Network (Ph.D. Jilin University, China 2012), p 25(In Chinese).

[2] H.Q Tang, C.Y Wang and B Wang, The effect of micro drill flute symmetry on drill fracture [J] The machine and hydraulic pressure Vol. 38(2010) No.16,p.1. (In Chinese).

[3] Y.H Zhou, J.X Zhang and W Tang, Ultra micro hole drilling and its key technology of printed circuit board Journal of Central South University (NATURAL SCIENCE EDITION). 2010 No.3, p.13-17(In Chinese).

[4] C.Y Wang, L.X Huang and X.J Zheng, Mapping model of drilling process and monitoring signal based on transient characteristics[J].Tool technology. 2010,No,1, p.121-124(In Chinese).

[5] Y Tang, H.K Ma and Q Wu, Simulation study on axial force and torque in micro hole drilling[J]. Tool technology. 2009,No.6, p.56-59(In Chinese). 
[6] Y.W Song, J.L Yao, Research on micro-hole drilling method [J]. Aeronautical Manufacturing Technology. Vol. 14(2012)p.26-31(In Chinese).

[7] Bathias, Pino, Fatigue of material and structures[M].National Defense Industry Press, 2016

[8] Y.H Sun, Research on Breakage Mechanism of Micro-drills and Drilling Forces Online Monitoring(Ph.D. Jilin University, China 2009),p.18.

[9] L.Z Liu, B.X Chen, The effect of micro-drill bit's helicoid symmetry to the micro-drill bit's rupture [J] Mechanics.Vol. 36(2009) No.11,p.30-31(In Chinese).

[10]L Dao, Mechanical behavior of engineering materials[M]. Mechanical Industry Press,2016. 